\title{
Analytical Electron Microscopy Investigation of Hardmetals
}

\author{
F. Arenas*, E. Barrios*, D. Field**, L. Bejar***. \\ *Department of Materials Technology, University Institute of Technology (IUT-RC), \\ PO Box 40347, Caracas 1040-A, VENEZUELA.
}

**School of Mechanics and Materials Engineering, 239C Dana Hall, Washington State University, P.O. Box 642920, Pullman, WA 99164-2920, USA.

*** Faculty of Mechanical Engineering, Michoacana San Nicolás de Hidalgo University, Morelia, Michoacán, C.P. 58000, MÉXICO

The interest in hardmetals as tool materials is known from some decades ago. However, the demand for improvement in mechanical fatigue, wear and corrosion properties is asking for submicron, ultrafine and nano-structured materials. In order to have a good mechanical properties microstructure correlation it is important to get a statistically acceptable result but, the complex microstructures obtained in these materials, mostly based on admixed sintered carbides, borides and carbonitrides, restricts such type of studies to the materials development research stage. New analytical techniques such as Electron Backscattering Diffraction (EBSD) coupled to SEM-EDX systems allows crystallographic and chemical evaluation of this fine microstructures in bulk samples.

This work comprises the microstructure evaluation of carbide-based hard metals by SEM-EDXEBSD and HRTEM complemented with XRD. Samples were prepared from pressureless vacuum sintered admixed WC, VC, TiC and Co sub-micron powders. Special care in the SEM bulk samples preparation for EBSD studies was taken in order to minimize the deformed surface layer. Previous works have recommended the use of ion polishing post mechanical polishing; however, the low quantity of "No solution" in the identification of patterns in the Euler angle maps implies an unstrained surface.

The phases crystallographic orientation maps in Fig. 1 show relevant microstructural parameters for sintered materials such as the high binder mean free path depicted by the Co phase distribution map, high connectivity or contiguity of the sub-micron WC phase and a high crystallographic misorientation existing in all three phases which is typical of sintered materials. On the other hand, individual phases grain size evaluation is more reliable than estimating it from either SE or BSE images. Phases with different chemistry as the $(\mathrm{CoW}) \mathrm{C}$ or $(\mathrm{WV}) \mathrm{C}$ might result with a similar gray level depending on the elemental atomic ratios. Figure 2 combines the different phases Euler angle maps overlapping with diffraction patterns for $\mathrm{WC}$ and $(\mathrm{W}, \mathrm{V})_{\mathrm{x}} \mathrm{C}_{1-\mathrm{x}}$. Due to the inexistence of ICDD data for the latter phase it has been used such of the WC for identification resulting in a good fit. It elucidates that $\mathrm{V}$ has a small influence on the WC crystal structure when entering in solution. 

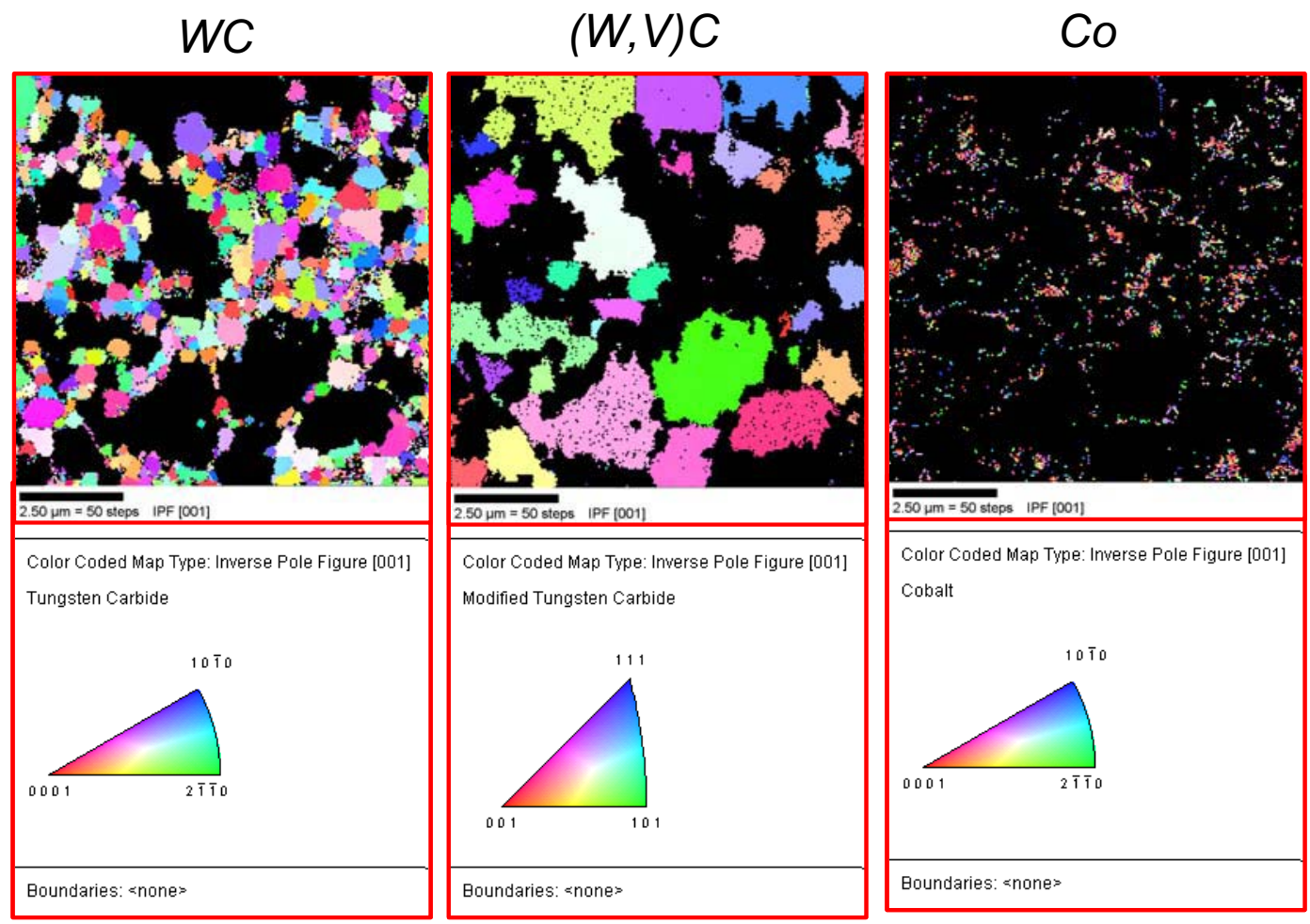

Figure 1. Orientation Map in WC-VC based hardmetals

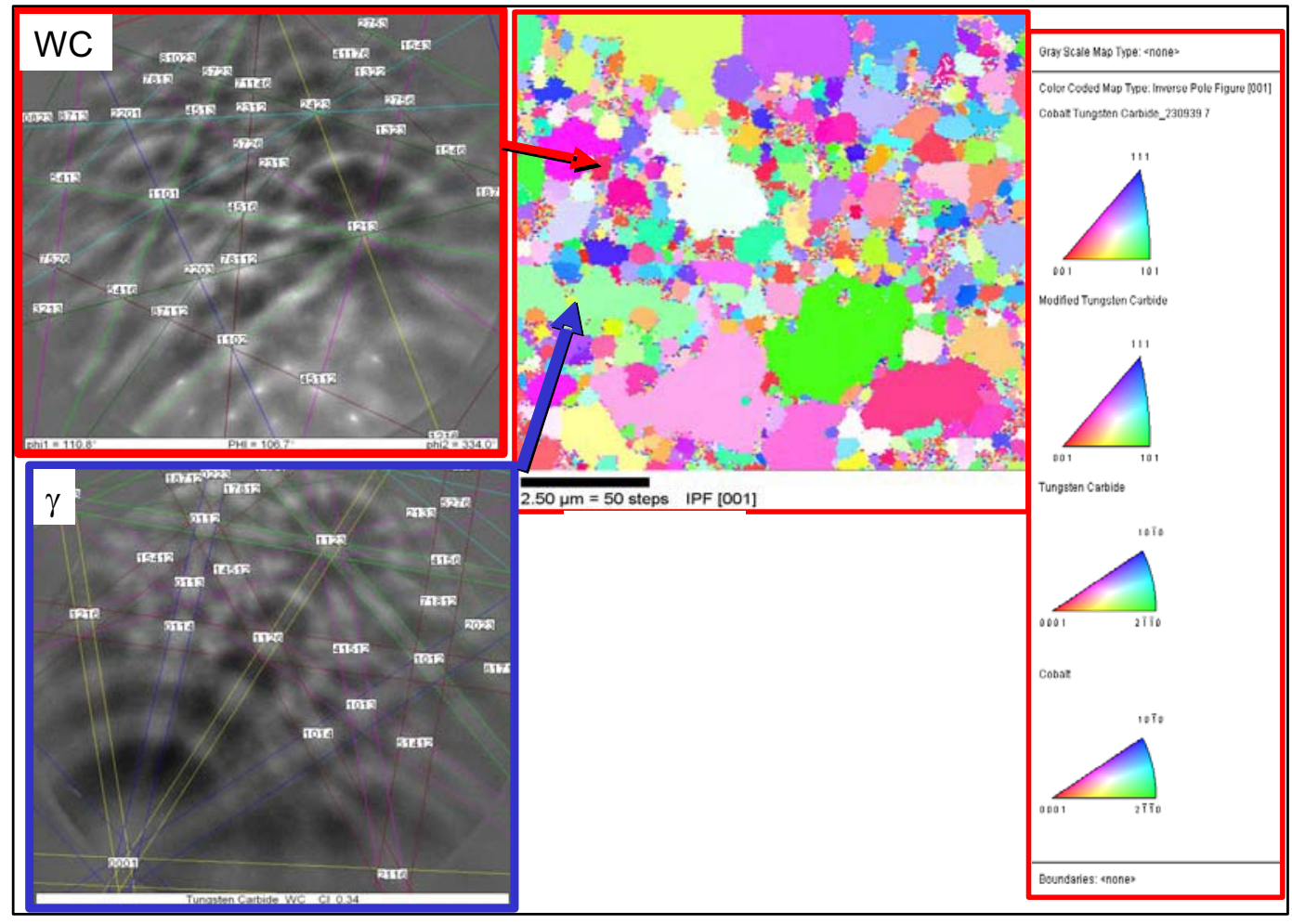

Figure 2. EBSKD patterns for single WC and double rich $\mathrm{W}$ carbide $(\gamma)$ phases. 